\title{
Current Status on Training and Education on Public and Healthcare Workers towards Tuberculosis Elimination: Case in South Korea
}

\section{Taeuk Kang}

Masan National Tuberculosis Hospital

\section{Seungkyu Park}

Masan National Tuberculosis Hospital

Sungweon Ryoo ( $\sim$ viweon@gmail.com )

Masan National Tuberculosis Hospital https://orcid.org/0000-0002-5085-0068

\section{Research Article}

Keywords: Tuberculosis, Healthcare workers, Training, Education, Status of Korea

Posted Date: February 22nd, 2021

DOI: https://doi.org/10.21203/rs.3.rs-246646/v1

License: (c) (i) This work is licensed under a Creative Commons Attribution 4.0 International License.

Read Full License 


\section{Abstract}

Tuberculosis, despite global effort to eliminate tuberculosis, still remains as a high burden to global public health. For tuberculosis elimination to be achieved, trainings and educations play pivotal role, tuberculosis control and prevention in particular. Internationally, several organizations are in charge of tuberculosis training and education program design, especially in its preparation and dissemination. In case of Korea, TB prevalence remains high, 59.0 per 100,000 in 2019. To overcome TB, institutes from both governmental and public sectors are organizing and providing tuberculosis-related training and education programs however, only few investigations on tuberculosis training in Korea was carried out, indicating difficulty lies in understanding and analyzing current TB training and education landscape. Hence, in this study, we have reviewed each institute and their roles in terms TB training and educational aspects as well as current tuberculosis status and strategies employed in Korea. Also, there are limitation lies in tuberculosis training and education thus, the call for global cooperation is necessary to response regional consideration against tuberculosis.

\section{Introduction}

Tuberculosis (TB), an infectious disease caused by Mycobacterium tuberculosis ( $M$. tb), is a serious public health burden in worldwide $(1,2)$. This is one of the leading causes of infection and death among curable infectious diseases; it is curable as antitubercular drugs are available and can be overcome by training and education $(3,4)$. Globally, although rate of prevalence have decreased in recent years, approximately 10.0 million are estimated to be suffering from TB infection with roughly 1.2 million of TB related deaths in 2020 according to the World Health Organization (WHO) (5). In case of Korea, referring Republic of Korea, 23,821 TB patients were newly notified in 2019 that is summed to 30,304 as total number of patients. This can also be presented as 46.4 and 59.0 per 100,000 for newly notified and total number of patients in 2019 respectively. As of 2018, 1,800 were reported as dead due to TB (6).

In 2000, the Millennium Development Goals (MDGs) was established to combat HIV/AIDS, TB, malaria and others by 2015 (7-9). In 2015, the United Nations Sustainable Development Goals (UN SDGs) superseded MDGs and aimed to eliminate HIV/AIDS, malaria, TB by 2030 with WHO End TB strategy (7, 10-12). Korea, with global trend toward TB elimination, had established comprehensive tuberculosis control plan since 2013. As of 2018, $2^{\text {nd }}$ plan was implemented (13) .

The success in terms of TB treatment can be influenced by insufficient knowledge of the public and Healthcare Workers $(\mathrm{HCWs})(4,14)$. Given that the provision of training to physicians can increase productivity and effectivity in TB treatment (15). In many countries, in order to improve and implement TB control strategies, numbers of training courses have been coordinated and organized both at international and national level. TB training, in general, has been included as part of basic curriculum for degree programs related to medical profession. Although these are provided to physicians, nurses, laboratory technicians in most of developing countries or countries where TB prevails, quality of TB trainings varies $(16,17)$. In the context of training for TB control, key challenge lies in spread of TB 
training while maintaining high-quality implementation (16). Currently numbers of organizations from government and public sectors such as Korea Disease Control and Prevention Agency (KDCA), Korea National Tuberculosis Association (KNTA), Korea Human Resource Development Institute for Health and Welfare (KOHI), Masan National Tuberculosis Hospital (MNTH) and Korea Nurses Association (KNA) have been organizing and/or providing TB training courses in Korea, where Korea refers to Republic of Korea.

Internationally, TB training and education and its evaluation have been widely investigated and these works are to be considered to contribute in terms of significant increase in TB treatment success rate $(4,18,19)$. Further, the analysis on emerging issues regarding TB training during evaluation can contribute in developing and refining training programs in future (20). For TB training and education to be evaluated, identifying current status of TB training is essential hence there is a need to identify the current status of related trainings. Also, it is high-lightened that improving and maintaining technical and theoretical aspects in TB of HCWs is, undoubtedly, important strategy and failure to do so will consequently lead to poor treatment performance. However, only handful of studies have attempted to investigate on current status of TB training in Korea. So far, there are several institutes involving TB training and education yet these institutes were not been analyzed and compared in Korea. Thus, in this study, we have discussed TB education and trainings, which reflects current TB status in Korea, provided by government and public organizations in Korea

\section{Main Text}

Status of tuberculosis in Korea

Korea had been suffered from TB that mortality rate of TB was estimated to 71.7 per 100,000 in 1942 and such mortality rate reached roughly 5 -fold higher than that of 1942 in 1954, 350 per 100,000, when the Korean war was over $(13,21)$. In 1954, total prevalence of TB was estimated as 1.3 million over 20 million in Korea $(21,22)$. Since of 1962 , Korea actively engaged in TB control program, resulted significant decreases in TB prevalence rate to 59.0 per 100,000 in $2019(6,23)$ (Figure 1). Despite significant declining of TB prevalence, Korea still shows the higher TB mortality rate than that of Organization for Economic Co-operation and Development (OECD), 4.0 versus 0.9 per 100,000 $(6,21)$.

Along with high prevalence of tuberculosis, Multi-Drug Resistant Tuberculosis (MDR-TB) rate of Korea of $4.1 \%$ is slightly higher than that of OECD average, $2.6 \%(21,24)$. The MDR-TB, as its unique feature, requires second-line antitubercular drugs along with prolonged treatment. It is widely known that second-line drugs are relatively less effective to that of first-line drugs, MDR-TB treatment often involves side effects and medical complications hence is major public health concern $(25,26)$. With effort to eliminate MDR-TB, cases of MDR-TB are decreased from 975 in 2011 to 580 cases in 2019. Similarly, XDR-TB cases was decreased from 140 to 33 cases from 2011 to 2019 (Figure 1). However, proportion of MDR-TB among foreigners was increased to $20.5 \%$ from $4.5 \%$ when 2019 was compared to 2011 , indicating an influx of tuberculosis cases from abroad (23). 
Latent Tuberculosis Infection (LTBI) is a state of $M$. tb infection without any clinical manifestation and/or symptoms of active TB $(27,28)$. Roughly one-thirds of global populations are estimated to be infected with LTBI globally according to WHO (29). Each individual infected with LTBI often unaware of the condition and among these individuals, roughly 5 to $15 \%$ of LTBI cases progress to active TB (30). This LTBI emerges as one of the most important sources of TB (31). In case of Korea back in 1960, the LTBI rate was estimated to be $64.2 \%$ when tuberculin skin test carried out. Such LTBI rate estimate is decreasing rapidly as it can be seen through periodic analysis that in 2016, LTBI rate was estimated to be $33.2 \%$ that is similar to that of global average $(23,32,33)$.

Strategies in Korea

TB still remains as a serious public health challenge in Korea (21). To overcome prevalent TB, Korea have employed several strategies and legislated laws to take action against TB for control and prevention purposes. Several acts such as the infectious disease control and prevention act in 1957 and the tuberculosis prevention act in 1968 were legislated to effectively control TB, specifying for the formulation and implementation of a comprehensive tuberculosis control plan for TB research, education, and training $(20,34)$.

One of the main strategies to TB elimination is Public-Private Mix (PPM) project, which was initiated in $2009(35,36)$. The objective of PPM project is to disseminate technical knowledge regarding TB to private hospitals by assigning trained TB management-specialized nurses for improvement in TB treatment success rate. As part of PPM project, registered nurses should be trained first in prior to be assigned as TB management-specialized nurses through TB management-specialized nurses training courses, provided by collaboration of KDCA, KNA and KNTA (36-38). Then these nurses are assigned in each hospital and are responsible for compliance management and TB prevention education provision $(21,35)$. As of 2019, 258 TB management-specialized nurses have been assigned in 150 private hospitals. These assignment of TB management-specialized nurses have increased national average of TB treatment success rate from $79.8 \%$ to $90.5 \%$ from 2012 to $2018(39,40)$.

Korea Disease Control and Prevention Agency

In 2003, the Korea Centers for Disease Control and Prevention (KCDC) was established to promote public hygiene and conduct prevention, investigation, quarantine, testing, and research on infectious diseases and chronic diseases $(41,42)$. In 2020, the KCDC was reformed and elevated to KDCA, which allows KDCA to stand as independent infectious disease control tower(43).

The one of the main roles of KDCA is TB control and prevention. The KDCA conducts activities related to TB control and prevention at national, provincial, and local levels such as TB surveillance, promoting TB training and prevention education. Hence, the KDCA closely engaged with city and provincial department of public hygiene to promote TB training to officers in public health centers (36). 
The KNTA is commissioned by KDCA or projects to conduct trainings on medical doctors and nurses, and related officers from public and private hospitals. The first TB trainings for Healthcare Workers were conducted in 1954; since 2000, the TB training and education programs broaden its coverage such as $B C G$ vaccine, TB-vulnerable social groups, and $\operatorname{LTBI}(36,44,45)$. Other than the training mentioned above, other training consists of TB management exclusively for public health doctors, including conscripted medical doctors, military medical officers, and medical doctors from public health centers, hospitals, and correctional facilities. This training program handles policy related to national tuberculosis program, treatment and diagnosis for TB, resistant TB, and LTBI as well as TB epidemiological investigation (44). The Korea Institute of Tuberculosis, a sub-affiliate of KNTA, is in charge of conducting technical support and related training for TB medical technicians as commissioned by KDCA and Ministry of Health and Welfare (MoHW) since $1954(44,46)$.

Even before KDCA was elevated, the KCDC was in charge for production and dissemination of publications related to TB. Since 2011, the KDCA are publishing Korean Guidelines for TB and National TB Control Guideline periodically. The national tuberculosis control guideline comprises of international and national TB status, national tuberculosis program, TB notification process, treatment and management and its related epidemiology for TB, MDR-TB, and LTBI patients as well as TB diagnostics. This guideline conveys up-to-date information related to TB to maximize performance in TB control and prevention (36). Also, training and educational materials such as laboratory manuals and others have been published (Table 1).

Table 1. Publications related to TB by KDCA from 2011 to 2020 


\begin{tabular}{|c|c|c|c|}
\hline No. & Guidelines and Manuals & $\begin{array}{l}\text { Co-publishing } \\
\text { institute* }\end{array}$ & $\begin{array}{l}\text { Year of } \\
\text { publication }\end{array}$ \\
\hline 1 & Korean Guidelines for Tuberculosis $\left(1^{\text {st }}-4^{\text {th }}\right.$ Ed) & 1 & $\begin{array}{l}2011- \\
2020\end{array}$ \\
\hline 2 & National Tuberculosis Control Guideline $\left(1^{\text {st }}-16^{\text {th }} \mathrm{Ed}\right)$ & $\mathrm{N} / \mathrm{A}$ & $\begin{array}{l}2003- \\
2021\end{array}$ \\
\hline 3 & $\begin{array}{l}\text { Tuberculosis "Close Contact Investigation on Crowded } \\
\left.\text { Facility" Major Casebook ( } 1^{\text {st }}-5^{\text {th }} E d\right)\end{array}$ & 2 & $\begin{array}{l}2014- \\
2019\end{array}$ \\
\hline 4 & Tuberculosis Control Guide for Medical Institutes & N/A & 2016 \\
\hline 5 & Manual of Laboratory Tests for Tuberculosis $\left(1^{\text {st }}, 2^{\text {nd }} \mathrm{Ed}\right)$ & 4,5 & $\begin{array}{l}2013- \\
2016\end{array}$ \\
\hline 6 & Tuberculin Skin Test Guidebook for examiners & 3 & 2019 \\
\hline 7 & $\begin{array}{l}\text { Family-contact Examination participating Medical Institutes. } \\
\text { Training material for Physicians }\end{array}$ & 6 & 2019 \\
\hline 8 & $\begin{array}{l}\text { Basic Training for Tuberculosis management-specialized } \\
\text { nurses }\end{array}$ & 6 & 2019 \\
\hline
\end{tabular}

*1. The Korean Academy of Tuberculosis and Respiratory diseases; 2. Ministry of Health and Welfare; 3. Korea Institute of Tuberculosis; 4. Korea National Institute of Health; 5. The Korean Society of Clinical Microbiology; 6. Korean National Tuberculosis Association

Korea Human Resource Development Institute of Health and Welfare

$\mathrm{KOHI}$ is an institution specialized in public health education and training to build and increase related officers' specialties and capabilities to successfully convey public health practices. The $\mathrm{KOHI}$ initially initiated its role, public health education and training in particular, as public health education division of National health center in 1946 and though centuries and numbers of reorganizations, KOHI was established in 2007 as quasi-governmental institution. Since its establishments, numbers of education and training programs were organized and conducted where categories of programs vary from general capability building education to public health and public health industry training (47).

Since even before establishment of $\mathrm{KOHI}$, Public health training department of Korea National Institute of Health, precursor of $\mathrm{KOHI}$, carried out public health trainings as commissioned by MoHW (47). The $\mathrm{KOHI}$ is also known to provide TB-specialized trainings and other related programs periodically (Table 2). As time passes from 2018, the training programs became more specified.

As of 2020, there are 3 representative TB-centered training programs provided by $\mathrm{KOHI}$ and these are TB diagnosis and interpretation, TB control, and advance TB control. 1) The TB diagnosis and interpretation program is offered to officers from public health centers and Public Health and Environmental Research Institutes, governmental institutes for infectious disease analysis and research as well as environmental and public health promotion and investigation, to increase basic acid-fast bacilli smear staining 
techniques as well as TB diagnosis techniques ; 2) In case of TB control program, this is prone to practical-oriented as these primarily focus on LTBI treatment principles, case study based on TB patient treatment, close contact investigation and epidemiology, and TB control status analysis. Also, this program recommends related programs such as advanced TB control program and getting to know tuberculosis series after completion as part of advanced TB control and treatment as well as continuing education; 3) For advanced TB control program, this program is intended for those who completed TB control program hence covers wider aspects of TB control such as establishment of TB prevention promotion strategies, figuring out of current status on local TB management as well as case study (47, 48). Upon completion of this program, the participants are expected to implement appropriate TB control and prevention strategies based on regional or local TB conditions. Also, understanding and designing TB-related promotional materials is one of the main capabilities that participants gain as go through the program (47).

TB is handled in other programs as well such as nosocomial infection control for medical doctors and infectious disease risk response program. These programs covers TB infection control in practice and TB containing sputum packaging while getting to know TB programs are introductory TB series that is generally intended for public hence consist of brief introduction, treatment, and prevention of TB and LTBI $(47,49)$.

Table 2. TB prevention education program provided by $\mathrm{KOHI}$ in 2020 


\begin{tabular}{|c|c|c|c|c|}
\hline No. & Participants* & Training program & Description & Hours \\
\hline 1 & Medical doctors & $\begin{array}{l}\text { Nosocomial infection } \\
\text { control for medical } \\
\text { doctors }\end{array}$ & $\begin{array}{l}\text { - National nosocomial infection } \\
\text { surveillance system } \\
\text { - National policy related to nosocomial } \\
\text { infection } \\
\text { - Infection control practice such as TB } \\
\text { and Carbapenem-Resistant } \\
\text { Enterobacteriaceae } \\
\text { - Infection control statistics } \\
\text { and analysis }\end{array}$ & 16 \\
\hline 2 & Public officers ${ }^{1,2}$ & $\begin{array}{l}\text { Tuberculosis } \\
\text { diagnosis and } \\
\text { interpretation }\end{array}$ & $\begin{array}{l}\text { - M. tuberculosis } \\
\text { characteristics and genotyping } \\
\text { - TB diagnosis and treatment } \\
\text { - TB-related biosafety }\end{array}$ & 21 \\
\hline 3 & Public officers ${ }^{3,4}$ & Tuberculosis control & $\begin{array}{l}\text { - National policy related to TB control } \\
\text { and prevention } \\
\text { - LTBI diagnosis and treatment } \\
\text { management } \\
\text { - TB prevention promotion } \\
\text { - TB epidemiological investigation on } \\
\text { crowded facilities }\end{array}$ & 21 \\
\hline 4 & Public officers ${ }^{1,5,6}$ & $\begin{array}{l}\text { Infectious disease } \\
\text { risk response } \\
\text { simulation }\end{array}$ & $\begin{array}{l}\text { - Sputum collection and clinical TB } \\
\text { sample packaging }\end{array}$ & 3 \\
\hline 5 & Public & $\begin{array}{l}\text { Getting to know } \\
\text { tuberculosis series }\end{array}$ & $\begin{array}{l}\text { - Introduction to TB and LTBI } \\
\text {-TB prevention, control, } \\
\text { treatment and management of } \\
\text { antitubercular drug side effects } \\
\text { - TB notification and case study }\end{array}$ & 3 \\
\hline 6 & $\begin{array}{l}\text { Tuberculosis } \\
\text { control program } \\
\text { participants }\end{array}$ & $\begin{array}{l}\text { Advanced } \\
\text { tuberculosis control }\end{array}$ & $\begin{array}{l}\text { - Utilization of public media for TB } \\
\text { prevention } \\
\text { - Analysis on TB status in local } \\
\text { governments } \\
\text { - Designing and analysis on } \\
\text { promotion for TB prevention }\end{array}$ & 12 \\
\hline
\end{tabular}


Masan National Tuberculosis Hospital

The MNTH was initiated on March of 1941 as a sanatorium with mission to treat and care TBsuffered veterans. Since May, 2002, it was renamed as MNTH and has become representative TBspecialized hospital in Korea.

The MNTH was an affiliated institution under MoHW and since of September of 2020 when KCDC was elevated to KDCA and turned to be independent from MoHW, the MNTH transferred and changed its affiliation from MoHW to KDCA. The MNTH conducts multiple roles other than TB treatment such as leading National Tuberculosis Program, performing TB research, and TB prevention education and training. The MNTH is a medical institute specialized in MDR-TB treatment (50).

The MNTH promotes public health through TB treatment and research thus advancing TB control and prevention capability (51). As of 2020, there are 2 TB medical specialist (TB-Spc) training institutes, the Seobuk hospital and the MNTH, remained(52) in Korea. Since the MNTH was designated as TB-Spc training institute by MoHW in 1993, institute trained total number of 14 TB-Spc since year of 1993 (50, 51). Other than TB-Spc training, the MNTH is actively educating HCWs and students for TB control and prevention on monthly basis starting from year of 2016 . So far, total number of 67,426 people were educated over 272 education sessions as of 2019, indicating significant contribution to TB control and prevention through education (51).

\section{Discussion}

Due active TB control and prevention activities conducted by the Korean government in terms of implementing TB related acts to eliminate TB, consequently, significantly improved TB status was observed recently $(13,21)$. Despite such, several TB statistics have shown that TB still remains as serious public health burden and Korea still has high TB incidence and mortality rate as compared to OECD average(5). Along with TB diagnosis and treatment, TB-related training and education unarguably function as pivotal role to tackle TB. Hence, the Korean government has exerted effort in TB-related training and education programs(13). For instance, $\mathrm{KOHI}$, a quasi-governmental institute funded by MoHW, is a representative example of institute designing and coordinating TB training and education programs. Such effort made is undoubtably significant and Korea as a country with proven history of TB control and prevention, it is thus noble responsibility of Korea to take in charge of and lead global TB elimination, especially supporting on Middle-and-Low-Income Countries (LMICs).

The TB-related training and education programs provided by $\mathrm{KOHI}$ are highly helpful as numbers of health care workers and public officers benefit every year. Yet, the programs impose limitations in that 
only a few programs provide practical TB diagnosis training for medical technologists. Also, there is a gap between the training program and actual routine hospital work as training needs to be related to the hospital setting. There are no published, systematic evaluation of programs provided by $\mathrm{KOHI}$, which creates difficulty in analyzing the quality and quantity of the programs as well as its effectiveness.

When designing and providing the TB training and educations, quality must be taken into considerations. The high-quality training has strong relationship with quality of treatment and care provided to patients. The quality of tuberculosis treatment is often assessed by what health care was provided to patients and the way was it completed (53). Hence, it is top priority to provide HCWs for high quality TB training programs containing different TB training curricula, especially in high TB burden countries. To maintain TB training program maintained as high-quality, quality assurance for TB training program is inevitable. As part of quality assurance, it is highly essential to conduct survey for participants feedback, performance test, pre-test, and post-test to evaluate quality of the program. Also, consultation and cooperation with international organizations such as WHO, the International Union Against Tuberculosis and Lung Disease (IUATLD), and related institutes are recommended (17).

The MNTH is national TB-specialized medical institute leading TB treatment, education, and research in Korea. The contributions attained by the MNTH over past 80 years has sufficiently proved for domestic achievements in TB treatment, education, and research. Also, these demonstrated that the MNTH can be improved further and has potential to stand frontline and lead TB control and prevention program towards TB elimination $(50,51)$. An instance of this was when MNTH designed and developed an advanced TB program specialized for TB treatment, nursing, control and prevention, as well as diagnosis. As stated above, there are certain shortcomings present even for TB training and education programs but there is high demand for practical TB related training, which can be directly translate training to be implemented to actual work.

Along with global trend against TB, the need for global cooperation and collaboration is intensified as time passes. For instance, the Koninklijke Nederlandse Centrale Vereniging Tuberculosis Foundation (KNCV) and IUATLD are internationally known for providing TB training programs with mission to achieve TB elimination through correcting irrelevant contents and ineffective or impractical methodologies related to TB as these can negatively influence on time and other resources; impact gets worsen especially in LMICs $(16,54-56)$. However, for course design, regional features should also be taken into consideration. The MNTH could satisfy the current demand to fill the gap of TB training and has competitive expertise to collaborate with international organizations to design appropriate regional-specific TB training programs.

\section{Conclusion}

Korea, since 1962, has been actively engaged in TB control and prevention programs. To overcome prevalent TB, the Korean government has implemented several TB control and prevention strategies, one of which is the provision of TB-related training and education. As TB training and education significantly influence TB control, they are considered an essential element. Several institutes 
designing and conducting TB training and education are as follows: KDCA, KNTA, KOHI, MNTH, KNA and other programs not mentioned in this paper. The trend of TB programs became diversified since 20th century, shifting from general TB training to ones on BCG vaccine, MDR-TB, LTBI, TB epidemiological investigation, and other TB related topics. However, despite recent improvements in TB training and education, limitations still exists and training programs can be developed further. Also, the call for global cooperation is highly demanded to support countries, especially low- and middle-income countries. Finally, due to the COVID-19 pandemic, most of TB trainings and educations were shifted to distancelearning programs. However, to train TB professionals in terms of clinical applicability, both theoretical knowledge and practical training needs to be carried out concurrently. With such perspectives, MNTH, as a leading national TB-specialized medical institute, has sufficient capability to satisfy the global needs and challenge the current limitations in TB training and education programs.

\section{Abbreviations}

IUATLD: International Union Against Tuberculosis and Lung Disease

KCDC: Korea Centers for Disease Control and Prevention

KDCA: Korea Disease Control and Prevention Agency

KNA: Korea Nurses Association

KNCV: Koninklijke Nederlandse Centrale Vereniging

KNTA: Korea National Tuberculosis Association

KOHI: Korea Human Resource Development Institute for Health and Welfare

LMICs: middle-and low-income countries

LTBI: Latent Tuberculosis Infection

M. tb: Mycobacterium tuberculosis

MDGs: Millennium Development Goals

MDR-TB: Multi-Drug Resistant Tuberculosis

MNTH: Masan National Tuberculosis Hospital

MoHW: Ministry of Health and Welfare

OECD: Organization for Economic Co-operation and Development

PPM: Public-Private Mix 
TB-Spc: TB medical specialist

TB: Tuberculosis

UN SDGs: United Nations Sustainable Development Goals

WHO: World Health Organization

\section{Declarations}

Ethics approval and consent to participate

Not applicable.

Consent for publication

Not applicable.

Availability of data and materials

Not applicable.

Conflict of Interest

The authors declare that they have no competing interests.

Funding

This research was financially supported by the Tuberculosis Clinical Research Program of the Clinical Research Center, Masan National Tuberculosis Hospital (4600-4631-304).

Author Contributions

T.K. and S.P contributed in conceptualization. T.K. conducted literature review. T.K and S.R prepared the manuscript. S.R was in charged for supervision and correspondence. Subsequently, all authors read and approved the final manuscript. 
Acknowledgements

Not applicable.

\section{References}

1. Dye C, Scheele S, Dolin P, Pathania V, Raviglione MC. Consensus statement. Global burden of tuberculosis: estimated incidence, prevalence, and mortality by country. WHO Global Surveillance and Monitoring Project. JAMA. 1999;282(7):677-86.

2. Dolin PJ, Raviglione MC, Kochi A. Global tuberculosis incidence and mortality during 1990-2000. Bull World Health Organ. 1994;72(2):213-20.

3. World Health Organization. The World health report : 2004 : changing history. Geneva, Switzerland; 20042004.

4. Shishi W, Imara R, Mishal K. Evaluating the impact of healthcare provider training to improve tuberculosis management: a systematic review of methods and outcome indicators used. Int $\mathrm{J}$ Infect dis. $2017 ; 56$.

5. World Health Organization. Global Tuberculosis Report 2020. Geneva, Switzerland; 2020.

6. Korea Centers for Disease Control and Prevention. Annual Report on the Notified Tuberculosis in Korea 2019. Osong, Korea; 2020. Report No.: 11-1352159-001424-10.

7. United Nations. The Millennium Development Goals Report 2015. Newyork, USA; 2015.

8. World Health Organization. Global tuberculosis control: surveillance, planning, financing. WHO Report 2013. Geneva, Switzerland; 2013. Report No.: WHO/HTM/TB/2008.393.

9. Wejse C. Tuberculosis elimination in the post Millennium Development Goals era. Int J Infect Dis. 2015;32:152-5.

10. United Nations. The Sustainable Development Goals Report 2020. Newyork, USA; 2020.

11. World Health Organization. WHO End TB Strategy. Geneva, Switzerland; 2015. Report No.: WHO/HTM/TB/2015.19.

12. Lonnroth K, Raviglione M. The WHO's new End TB Strategy in the post-2015 era of the Sustainable Development Goals. Trans R Soc Trop Med Hyg. 2016;110(3):148-50.

13. Cho KS. Tuberculosis control in the Republic of Korea. Epidemiol Health. 2018;40:e2018036 [Korean language].

14. Wu PS, Chou P, Chang NT, Sun WJ, Kuo HS. Assessment of changes in knowledge and stigmatization following tuberculosis training workshops in taiwan. J Formos Med Assoc. 2009;108(5):377-85.

15. Marjolein D, Jan Willem H. Improving health worker performance: in search of promising practices. Geneva, Switzerland; 2006. 
16. World Health Organization. Training for better TB control: human resource development for TB control: A strategic approach within country support. Geneva, Switzerland; 2002. Report No.: WHO/CDS/TB/2002.301.

17. Awofeso N, Schelokova I, Dalhatu A. Training of front-line health workers for tuberculosis control: lessons from Nigeria and Kyrgyzstan. Hum Resour Health. 2008;6:20.

18. Main S, Lestari T, Triasih R, Chan G, Davidson L, Majumdar S, et al. Training for Tuberculosis Elimination in Indonesia: Achievements, Reflections, and Potential for Impact. Trop Med Infect Dis. 2019;4(3).

19. Kilicaslan Z, Kiyan E, Erkan F, Gurgan M, Aydemir N, Arseven O. Evaluation of undergraduate training on tuberculosis at Istanbul Medical School. Int J Tuberc Lung Dis. 2003;7(2).

20. Infectious Diseases Control and Prevention Act [Republic of Korea], (2020).

21. Kim JH, Yim JJ. Achievements in and Challenges of Tuberculosis Control in South Korea. Emerg Infect Dis. 2015;21(11):1913-20.

22. Korea National Tuberculosis Association. A history of tuberculosis in Korea Seoul. Korea; 1998 [Korean language].

23. Cho KS. Tuberculosis Control in the Republic of Korea. Health Soc Welf Rev. 2017;37(4 [Korean language]).

24. Cho KS, Kim NH. Multidrug-resistant tuberculosis status and performance of the healthcare review committee for new drugs for MDR-TB in the Republic of Korea. Osong, Korea; 2017 [Korean language].

25. Dheda K, Gumbo T, Maartens G, Dooley KE, McNerney R, Murray M, et al. The epidemiology, pathogenesis, transmission, diagnosis, and management of multidrug-resistant, extensively drugresistant, and incurable tuberculosis. Lancet Respir Med. 2017.

26. Matteelli A, Migliori GB, Cirillo D, Centis R, Girard E, Raviglion M. Multidrug-resistant and extensively drug-resistant Mycobacterium tuberculosis: epidemiology and control. Expert Rev Anti Infect Ther. 2007;5(5):857-71.

27. Dye C, Glaziou P, Floyd K, Raviglione M. Prospects for tuberculosis elimination. Annu Rev Public Health. 2013;34:271-86.

28. Yeon JH, Seong H, Hur H, Park Y, Kim YA, Park YS, et al. Prevalence and risk factors of latent tuberculosis among Korean healthcare workers using whole-blood interferon-gamma release assay. Sci Rep. 2018;8(1):10113.

29. World Health Organization. Guidelines on the management of latent tuberculosis infection. Geneva, Switzerland; 2015. Report No.: WHO/HTM/TB/2015.01.

30. Getahun H, Matteelli A, Chaisson RE, Raviglione M. Latent Mycobacterium tuberculosis infection. N Engl J Med. 2015;372(22):2127-35.

31. Murray CJ. Shifting to Sustainable Development Goals-Implications for Global Health. N Engl J Med. 2015;373(15):1390-3. 
32. Korea Centers for Disease Control and Prevention, Korea National Tuberculosis Association. 7th National Health Nutrition Investigation. Cheongju, Korea; 2016 [Korean language].

33. Ministry of Health and Welfare, Korea National Tuberculosis Association. 7th National Tuberculosis Investigation. Gacheon, Korea; 1996 [Korean language].

34. Tuberculosis Control and Prevention Act [Republic of Korea], (2020).

35. Kim S. Economic evaluation and effectiveness of public-private mix for tuberculosis care and control. Osong, Korea; 2011 Report No.: 2011E3100200 [Korean language].

36. Korea Centers for Disease Control and Prevention. 2020 National Tuberculosis Control Guideline. Osong, Korea: Korea Disease Control and Prevention Agency; 2020. Report No.: 978-89-6838-764-7 [Korean language].

37. Korea Ministry of Health and Welfare, Korea Centers for Disease Control and Prevention. 1st Comprehensive Tuberculosis control plan and guideline of establishment of local governments performance plan (2013-2017). Cheongju, Korea; 2013 [Korean language].

38. Korea National Tuberculosis Association. 2018 Annual Project Report on Korea National Tuberculosis Association. Seoul, Korea; 2018 [Korean language].

39. Korea Centers for Disease Control and Prevention. Tuberculosis Control Newsletter 2018 [Korean language].

40. Min J, Kim HW, Koo HK, Ko Y, Oh JY, Kim J, et al. Impact of COVID-19 Pandemic on the National PPM Tuberculosis Control Project in Korea: the Korean PPM Monitoring Database between July 2019 and June 2020. J Korean Med Sci. 2020;35(43):e388.

41. Korea National Institute of Health. Korea National Institute of Health Osong, Korea: Korea National Institute of Health; 2019 [Available from: http://www.nih.go.kr/ [Korean language].

42. Korea Centers for Disease Control and Prevention. Korea Disease Control and Prevention Agency Osong, Korea: Korea Disease Control and Prevention Agency; 2019 [Available from: http://www.kdca.go.kr/cdc/ [Korean language].

43. Government Organization Act [Republic of Korea], (2020).

44. Korea National Tuberculosis Association. Korea National Tuberculosis Association Seoul, Korea: Korea National Tuberculosis Association; 2020 [Available from: https://www.knta.or.kr/ [Korean language].

45. Korea Ministry of Health and Welfare, Korea Centers for Disease Control and Prevention. 2nd Comprehensive Tuberculosis control plan and guideline of establishment of local governments performance plan (2018-2022). Cheongju, Korea; 2018 [Korean language].

46. Ryoo S, Kim HJ. Activities of the korean institute of tuberculosis. Osong Public Health Res Perspect. 2014;5(Suppl):S43-9.

47. Korea Human Resource Development Institute for Health and Welfare. Korea Human Resource Development Institute for Health and Welfare Osong, Korea: Korea Human Resource Development 
Institute for Health and Welfare; 2020 [18 Dec]. Available from: https://www.kohi.or.kr/index.do [Korean language].

48. Public Health and Environmental Research Institute Act [Republic of Korea], (2020).

49. Korea Human Resource Development Institute for Health and Welfare. 2020 Program Guide. Osong, Korea: Korea Human Resource Development Institute for Health and Welfare; 2020 [Korean language].

50. Masan National Tuberculosis Hospital. Masan National Tuberculosis Hospital Masan, Korea: Masan National Tuberculosis Hospital; 2020 [Available from: http://www.mnth.go.kr/main.do [Korean language].

51. Masan National Tuberculosis Hospital. 2019 Annual Report on Masan National Tuberculosis Hospital. Masan, Korea; 2020. Report No.: 11-1352316-000002-10 [Korean language].

52. Ministry of Health and Welfare. Status of medical specialist training hospitals Seoul, Korea: Ministry of Health and Welfare; 2020 [Available from: http://cgmt.or.kr/training/personStatus [Korean language].

53. Mainz J. Defining and classifying clinical indicators for quality improvement. Int J Qual Health Care. 2003;15(6):523-30.

54. KNCV Tuberculosis Foundation. KNCV Tuberculosis Foundation Maanweg, Netherland: KNCV Tuberculosis Foundation; 2020 [Available from: https://www.kncvtbc.org/en/.

55. International Union Against Tuberculosis and Lung Disease. International Union Against Tuberculosis and Lung Disease Paris, France: International Union Against Tuberculosis and Lung Disease; 2020 [Available from: https://theunion.org/.

56. Morgan CJ, Deutschmann PW. An evolving model for training and education in resource-poor settings: teaching health workers to fish. Med J Aust. 2003;178(1):21-5.

\section{Figures}




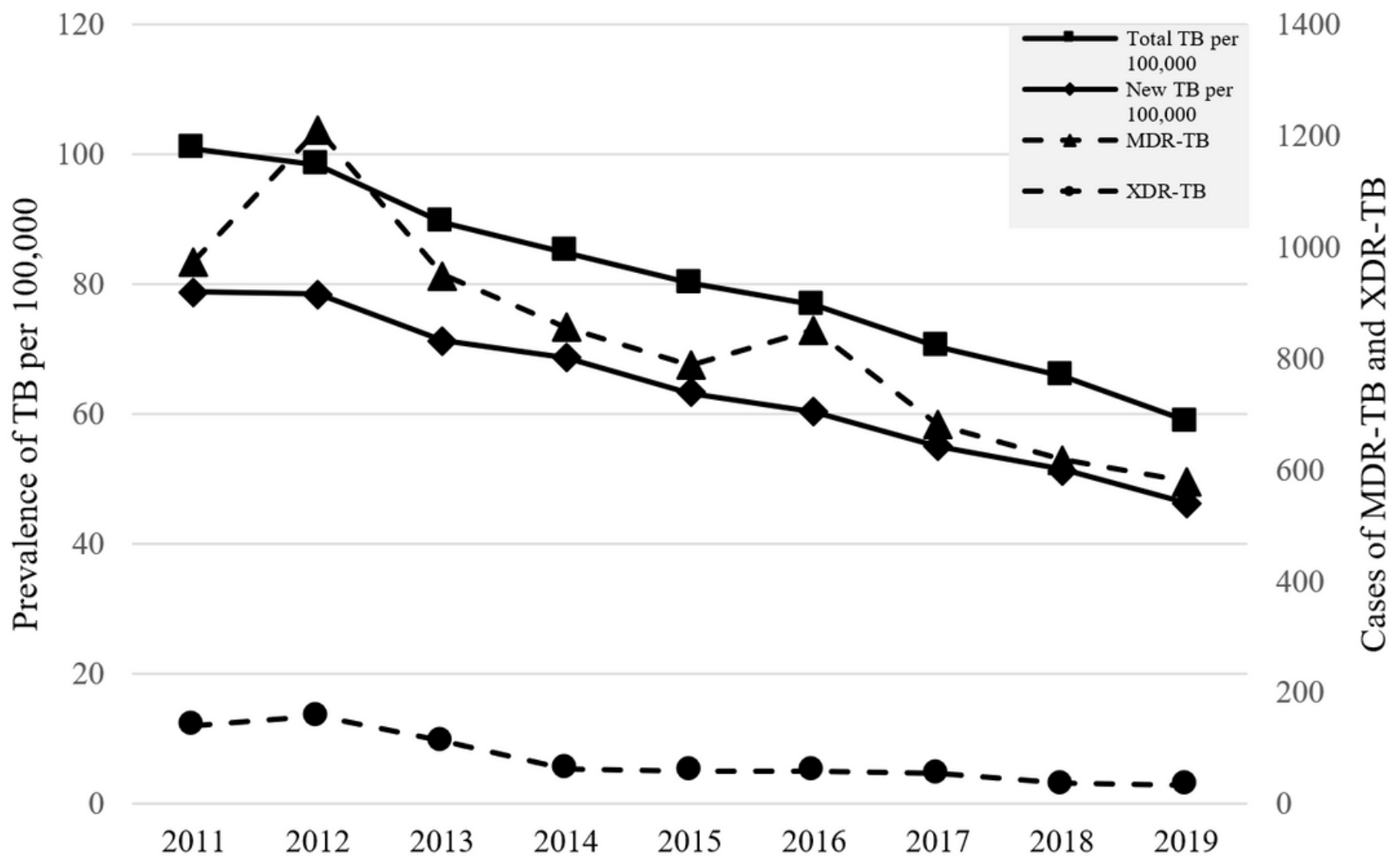

Figure 1

Notified TB cases in korea from 2011 to 2019; square represents total TB cases per 100,000; diamond represents new TB cases per 100,000; triangle represents MDR-TB cases; circle represents XDR-TB cases 